\title{
Staging Migration (in) Museums A Reflection on Exhibition Design Practices for the Representation of Migration in European Contemporary Museums
}

\author{
Francesca Lanz* Politecnico di Milano
}

\begin{abstract}
Migration, cultural diversity and the growing ethnic-cultural mix that characterize contemporary society are nowadays a key issue for European museums. Since the 1990s a rich theoretical debate on the subject has been developed by scholars and the museums community at large, several 'migration museums' have been opened across Europe, while, most recently, a number of museums have been reassessing their collections and galleries in relation to issues such as emigration, immigration, cultural diversity and intercultural dialogue. This article aims at contributing to the debate with a museographical reflection on the subject by exploring its design implications, to finally suggest that the challenge for representing migration in museums does not only concern the museum's curatorial approaches but also requires the development of new exhibition settings and practices.
\end{abstract}

Keywords: exhibition design; migration museums; museography

\begin{abstract}
A Museographical Approach
This article deals with the issue of the representation of migration with the aim of contributing to the debate with a museographical ${ }^{1}$ reflection on the subject. The underlying premises of what follows are drawn from a growing body of writing and research, including work on migration and globalization, which address the impact of cultural and political change on the museum's role, mission and practices. ${ }^{2}$ However the paper does not extend to an investigation of societal issues and how they affect museum work. Nor does it present ideas for new forms of curatorial practice. Rather it examines the design implications of such changes - a barely explored yet relevant aspect of the subject matter. As Sharon Macdonald pointed out in her article reflecting on the role and potentialities of museums for the articulation of new identities in a post-national and trans-cultural perspective, 'visual and spatial features of museums also have implications for conceptions of identity' (2003: 3). If, drawing on Macdonald herself, the museographical nineteenth-century model based on the detachment of the viewer and the possibility of offering a privileged viewpoint, mirrored a premise of objectivity and a traditional conception of identity as unique, homogeneous and consolidated (Hooper-Greenhill 1992; Basso Peressut 2005; Giebelhausen 2006a; 2006b), which kind of exhibition design and museum organization can be coupled with the new multiple and heterogeneous state of being of contemporary cultural conditions?

After a brief introductory overview aimed at setting the framework of the paper by presenting the emergence of issues related to migration in European museums in the context of the present political and social multi-cultural scenario, the article analyzes the display settings of selected migration museums - a relatively new museum type that has been spreading throughout Europe since the early twenty-first century - focusing in particular on emigration museums. Through the observation of paradigmatic examples, the article illustrates the most established and widely used exhibition features of these museums. Thereafter, by comparing their design to selected exhibitions devoted to immigration, differences and commonalities will be outlined, with a view to identifying recurrent practices in the design of migration museums as well as weaknesses and potentialities. The paper goes on to suggest that the challenge for representing migration in museums does not only concern the museum's approaches. Nor
\end{abstract}


can it can simply result in the implementation of codified exhibition formats. It also requires the development of new exhibition and display settings supporting innovative practices and programmes, on the assumption that the 'issue of migration does seem to demand experimental approaches with respect to both aesthetics and narratives [...] and seems to generate from within itself a questioning of how to tell stories in a museum space, how to engage the audience and how to convey information or knowledge' (Poehls 2011: 341, 348).

\section{Museum and Migration}

In the last twenty years the traditional understanding of museums and their role in our contemporary society has been radically questioned both in theory and in practice. The interpretation of museums as static repositories of historical and artistic treasures and sites of worship, is being gradually overtaken by a new comprehension of museums as public services and social agents, which do not only have a preeminent conservation role, but also - and primarily - an important educational, political and social role within contemporary society (e.g. Vergo 1989; Hooper-Greenhill 1992; Karp et al. 1992; Macdonald and Fyfe 1998; Sandell 2002; Marstine 2006; Macdonald 2006; Knell et al. 2007; Marstine et al. 2013). Today, museums are more and more asked to 'keep up with' the wider society in which they find themselves, to deal with contemporary issues and engage in dialogue with local communities. As they give up their presumed super partes objectivity and universalism, they are expected to take and declare a political stance, not only by reacting to contemporary matters, but also by contributing to the shaping of society and becoming forums able to accept and build on dissent. ${ }^{3}$

Today's socio-cultural scenario is constantly and deeply changing under the influence of many factors, including intensive migration flows, the accelerated mobility and fluid circulation of information, cultures, people, ideas and goods, and an increasingly number of cultural encounters and cross-fertilizations. Migrations have occurred throughout human history and they have informed the development of every culture and society in any historical and political period. However, today their dynamics act at an unprecedented speed and magnitude, producing a substantial shift in contemporary political, cultural and societal conditions and in the processes of identity formation (Rutherford 1990; Bhabha 1994; Appadurai 1996, Welsch 1999; Chambers 2012). Questions and concerns related to migration, intercultural dialogue and cultural differences are therefore some of the most compelling challenges that cultural and political institutions face nowadays, including museums.

Migration, cultural diversity and the growing ethnic-cultural mix that characterize contemporary society have indeed become a key issue for European museums. Since the 1990s a rich theoretical debate on the subject has been developed by scholars and the museums community at large; several 'migration museums' have been opened across Europe, and, most recently, a number of museums have been questioning their consolidated approaches and practices in relation to the aforementioned socio-cultural scenario. It stands to reason that all these issues represent new challenges for museums, which require new models and tools to tackle them. This is resulting in the promotion of temporary exhibitions, educational programmes and outreach projects that investigate issues such as emigration, immigration, cultural diversity and intercultural dialogue from many different perspectives. Many museums are experimenting with new curatorial practices - such as co-curating, participative collecting, international and interdisciplinary networking or artistic cooperations - as well as reorganizing and reinterpreting their collections and renovating their galleries, with the aim of considering migration and cultural diversity as part of the story they tell (Karp and Lavine 1991; Karp et al. 1992; Sandell 2002; Karp et al. 2006; Watson 2007; Innocenti 2012; Whitehead et al. 2012; Basso Peressut et al. 2013; Chambers et al. 2014; Gouriévidis 2014; Innocenti 2014; Lanz and Montanari 2014; Whitehead et al. 2015). ${ }^{4}$

In thinking generally about innovation in museum programmes, missions, strategies and tools, it is important not to underestimate the crucial importance of the connections between the museum's design and the museum's contents, as well as the intellectual and expressive aspects of the exhibition design itself since, 'the architecture determines the viewing conditions both conceptually and physically. It not only frames the exhibits but also shapes our visitor experience' (Giebelhausen 2006a: 42). This paper focuses on that aspect. Aware of the 
troublesome nature of the topic, i.e. museums and migrations, I reflect upon the exhibition design practices implemented in single-subject museums and galleries devoted to migration, with the aim of generating further thoughts on the role of the museographical project in relation to current developments in museums.

\section{Recurrent Exhibition Practices in Emigration Museums}

As previously mentioned, several new migration museums have been opened across Europe in the past ten years (Baur 2009; 2010a; 2010b; 2013; Cimoli 2013). Some of these museums are devoted to the history of emigration, some others aim at exploring immigration in history and contemporaneity, and recently, some of the earliest ones have expanded their exhibition to include sections on immigration. A large number of factors including the need to react to a shifting social and cultural context, the attempt to promote a more open attitude and acceptance toward contemporary migration phenomena, the effect of the past 'museum boom', and the progressive development of social history museums, led to an increase in the number of migration museums in Europe. Indeed it might be argued that a 'new museum type' is emerging.

European migration museums are usually relatively young institutions most of which are devoted to the description of the history of emigration considered as a moment of local history worthy of being preserved and transmitted as part of the common memory of a specific community and in relation to its potential relevance in the construction and reinforcement of the local identity. Despite the natural differences derived from each museum's specific context and origins, most of them have much in common with respect to their focus, mission and curatorial practices as well as in matters of design. Moreover, European museums have often been conceived in the light of similar examples overseas - such as the Ellis Island Museum in New York, the Pier 21 Museum in Halifax or the Immigration Museum in Melbourne - though the latter focus on immigration rather than on emigration. Therefore, one can assume that, in examining the exhibition design of these museums, it is possible to identify some recurring elements that structure and characterize their display and narrative, spurring the rise of a codified language.

\section{Master-Themes Structuring the Museum Itinerary}

First, we can distinguish some master-themes, typically the topic of the voyage or of the border crossing. These themes basically function as threads for the museum's narration, which is often developed chronologically, recounting the experience of migrating. These topics, as Joachim Baur also observes, occasionally do also offer the spark for wider discourses. The theme of the border, for example, may foster reflections on the issue of migration policies, on the changing definition of wanted/unwanted migrants, or on inclusion and exclusion dynamics, while the travel can be used as a metaphorical rite de passage representing a process of transformation and change (Baur 2010b).

A well-known example is the German Emigration Center in Bremerhaven, whose permanent exhibition, inaugurated in 2005, depicts the history of emigration from Bremerhaven to the New World between 1830 and 1974. The exhibition, which is designed by Studio Andreas Heller Architects and Designers and has quickly become a reference point for the depiction of migration, narrates step-by-step the migratory experience of people leaving Germany: from the departure from Bremerhaven wharf to Ellis Island checkpoint and the United States of America (Bongert 2014, Cimoli 2013, Eick 2013). As Christoph Bongert, curator at the German Emigration Center, pointed out,

there is an obvious "grand" narrative: that of the voyage (...) [which] is not a chronologically consistent one: visitors start on the wharf around 1890, travel through different times before and after, and eventually arrive at Ellis Island in 1907. (...)This narrative is structured by a dramaturgy according to the components of a voyage: the parting, the crossing and the arrival. On the one hand, this dramaturgy serves to facilitate the visitors' empathy with "their" emigrant, but on the other hand, it also integrates sites of reflection that disturb the mere Einfühlung [empathy] (Bongert 2014). 


\section{Iconic Objects Orienteering the Visit}

These thematic understructures are often visually connected with the staging of a series of iconic objects, typically personal objects such as luggage, travel documents, migrants' letters, passports, clothes or baby toys. ${ }^{5}$ These objects are frequently used for their effective visual impact and immediate connection with the exhibition themes; they seldom have an historic or artistic value in themselves, being often copies or reproductions, and their significance mainly resides in the meaning they embody, the memories they evoke, and in their very scenographical impact.

These objects are largely present in exhibitions about emigration where they are often presented through some recurring mise-en-scène. Commonly, they are displayed in accumulation as the piles of luggage in the Bremerhaven Museum or those in the Ballinstadt Emigration Museum in Hamburg. In some cases they become themselves part of the display apparatus, serving as showcases containing several objects, pictures, videos and other media, such as in the exhibition Diàlegs Migrants at the Museum of the History of Immigration in Catalonia in Barcelona (17 May - 23 July 2013), where suitcases were used as display cases containing images and video-interviews. Another interesting example is represented by the exhibition Jeder ist ein Fremder - fast überall (2003-2007), a three-year-long travelling exhibition on European migration over time, where showcases were designed in a metaphorical and practical way as trunks: self-bearing elements containing several objects, pictures, videos and other media. ${ }^{6}$ In other cases, these objects are used as digital or analogical interactive devices serving as entry points to additional contents via visitors' interaction (e.g. browsing letters and accessing more details about the author's story, touching the replica of a toy to listen to its owner's vicissitudes, using a passport shaped device to discover real biographies of emigrants, etc.).

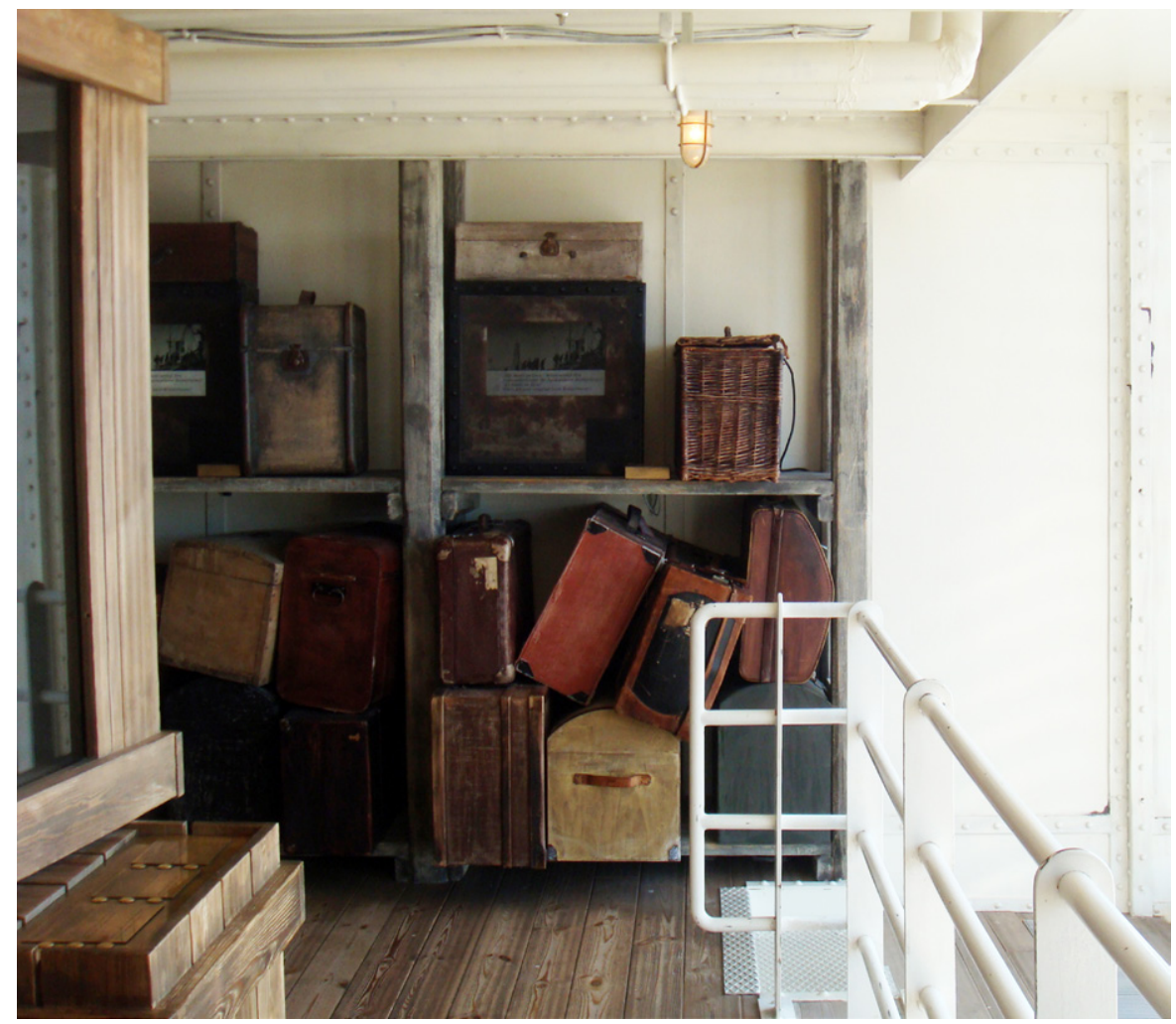

Figure 1: German Emigration Centre 


\section{Immersive Spaces and Interactive Devices Fostering Visitors' Involvement}

Iconic objects have a peculiar evocative power, which is exploited by the exhibition design with a double purpose: on the one hand it provides visual support to the museum narrative, on the other it contributes at engaging the audience in the narration on an intellectual, emotional and also physical level. Indeed, engendering an immediate and emotional connection to the stories being told is a common and declared aim of these exhibitions, which often draw upon display settings and solutions specifically designed for this purpose. Among these, the most recurring solution is the implementation of what we may call immersive spaces: full-scale exhibitions with a very scenographic impact, which are oftentimes walkable and usually staged resorting to theatrical techniques, including original furniture and replicas, lights, projections, sounds, and also walk-ons, where the visitor does not recognize himself/herself anymore as a spectator, but rather becomes a character in the story.

Most emigration museums and galleries include such spaces. To mention a few examples: the gallery Titanic, return to Cherbourg at La Cité de la Mer in Cherbourg, includes a large section devoted to emigration, developed, as the whole exhibition, with a wide use of reconstructions, interactive devices, audio and video testimonies and even holograms; and the exhibition about Italian emigration MeM-Memory and Migration at the Galata Museo del Mare e

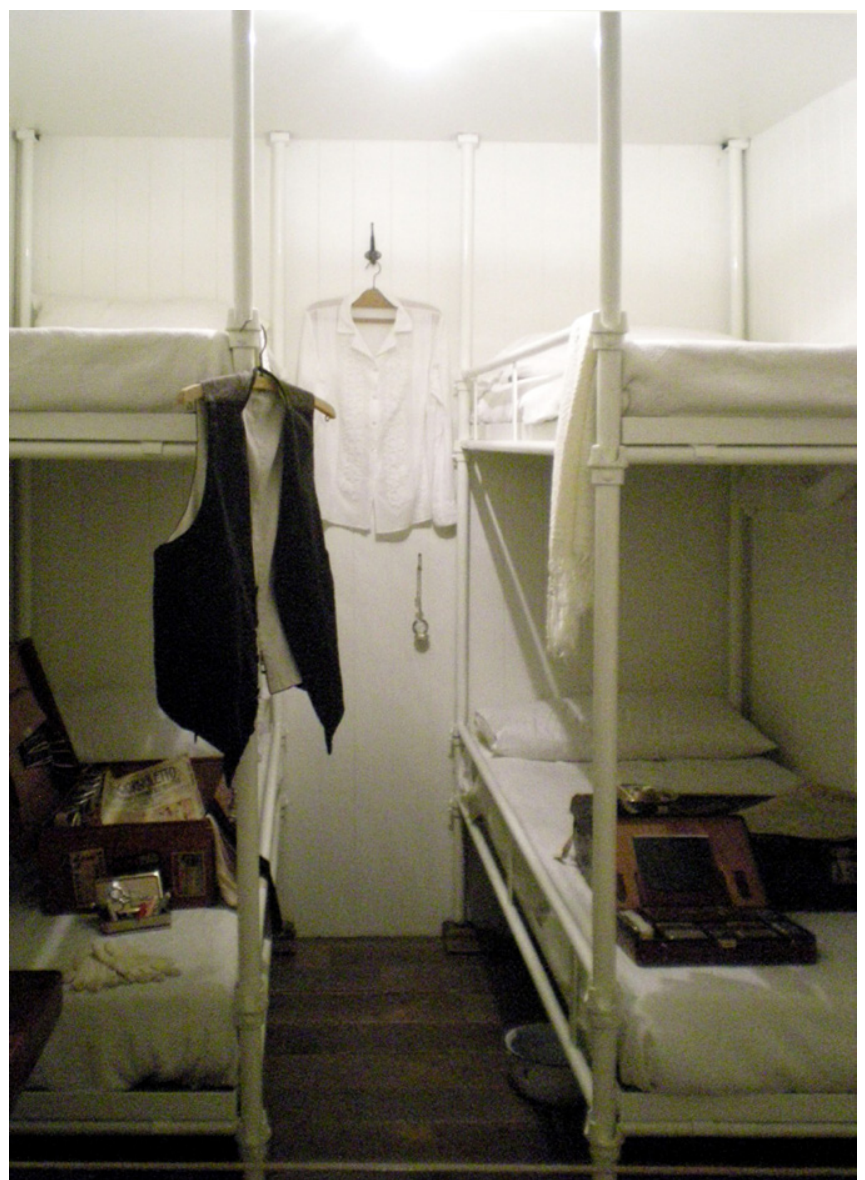

Figure 2: Genoa Mem 1 delle Migrazioni in Genoa also frequently resorts to full-scale immersive spaces, such as the reproduction of emigrants' quarters on board of an ocean liner. Here, by sitting on bunkbeds, the visitor activates an audio tape with the voice of an actor who recites the letter of an immigrant describing his/her voyage, dreams and expectations about the future.

Other solutions e ncompass the implementation of roleplaying games dynamics; the extensive use of personal objects and audio-video testimonies with a very high emotional impact; interactive and hands-on devices often implemented through the use of new technologies; and the inclusion of genealogical search engines to eventually retrace one's own migrant background. All these devices aim at transforming the museum visit into an engaging experience by turning the visitor from a viewer into a user, who is no longer detached from what is being represented, but actively part of it, touching, listening, and playing a role in the exhibition. 


\section{A Resonant Spatial Framework Supporting the Museum Narrative}

The architectural context of the museum complements the visual communicative apparatus of these exhibitions and further amplifies their poignancy. Migration museums are in fact usually located in places that have a history related to migration, such as port cities, docklands, border or departure towns, and areas which have suffered intense migration flows. Moreover, whenever possible, the building hosting the museum is a very emblematic building, connected with stories of migration and bearing itself a memory of migration. Beside the widely known and paradigmatic example of the Ellis Island Museum, amongst the European cases it is worth mentioning the Red Star Line Museums, located in the neighbourhood of the old port of Antwerp, in the former premises of the Red Star Line, a shipping company whose activity was largely based on the profitable transport of emigrants from Belgium to Canada and the United States. The museum comprises three original warehouses originally devoted to medical examinations, administrative checks and luggage disinfection, which have been renovated while preserving their original Art Deco architecture and decoration. Another example is represented by the Museum of the History of Immigration in Catalonia, in Barcelona, where a section of the exhibition is set up on the carriages of the El Sevillano train that were used by migrants who moved to Catalonia from the south of Spain during the twentieth century.

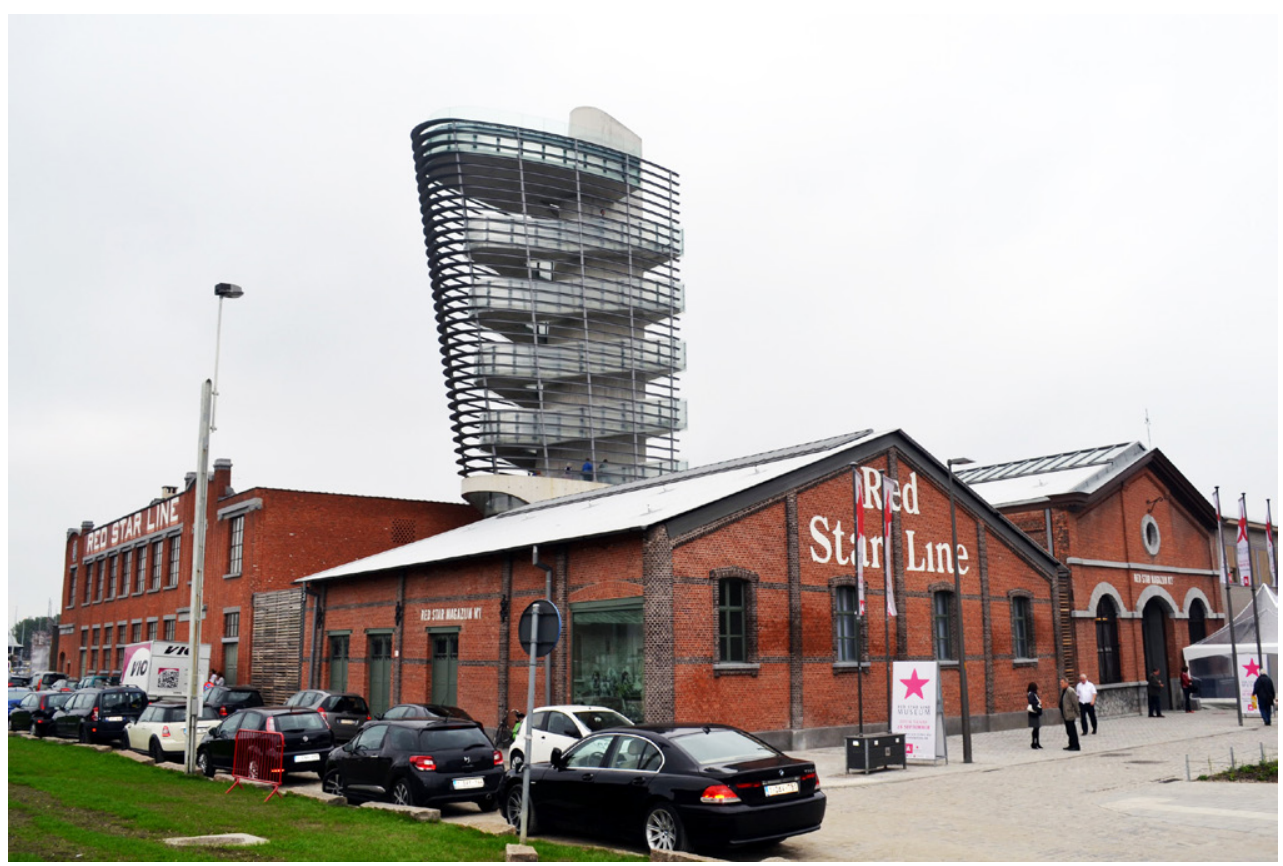

Figure 3: Red Star Line Museum

The architectural project of these museums is usually aimed at restoring disused or abandoned buildings and turning them into museums, thus recovering them from the wear and forgetfulness of time. The museographical project is also aimed at emphasizing the buildings' symbolic value by enhancing their evocative power and disclosing the memory they preserve (e.g. investing in the restoration of specific rooms of the building; labelling parts of it to explain its history; leaving empty rooms as they are themselves core to the exhibit; designing passages, itineraries and perspectives that enhance the architectural space and the spatial features of the museum; etc.). Hence, the museum building becomes itself part of the collection, and, at the same time, it creates a highly resonant framework for the exhibition, contributing to the explication and effectiveness of the whole narration. 


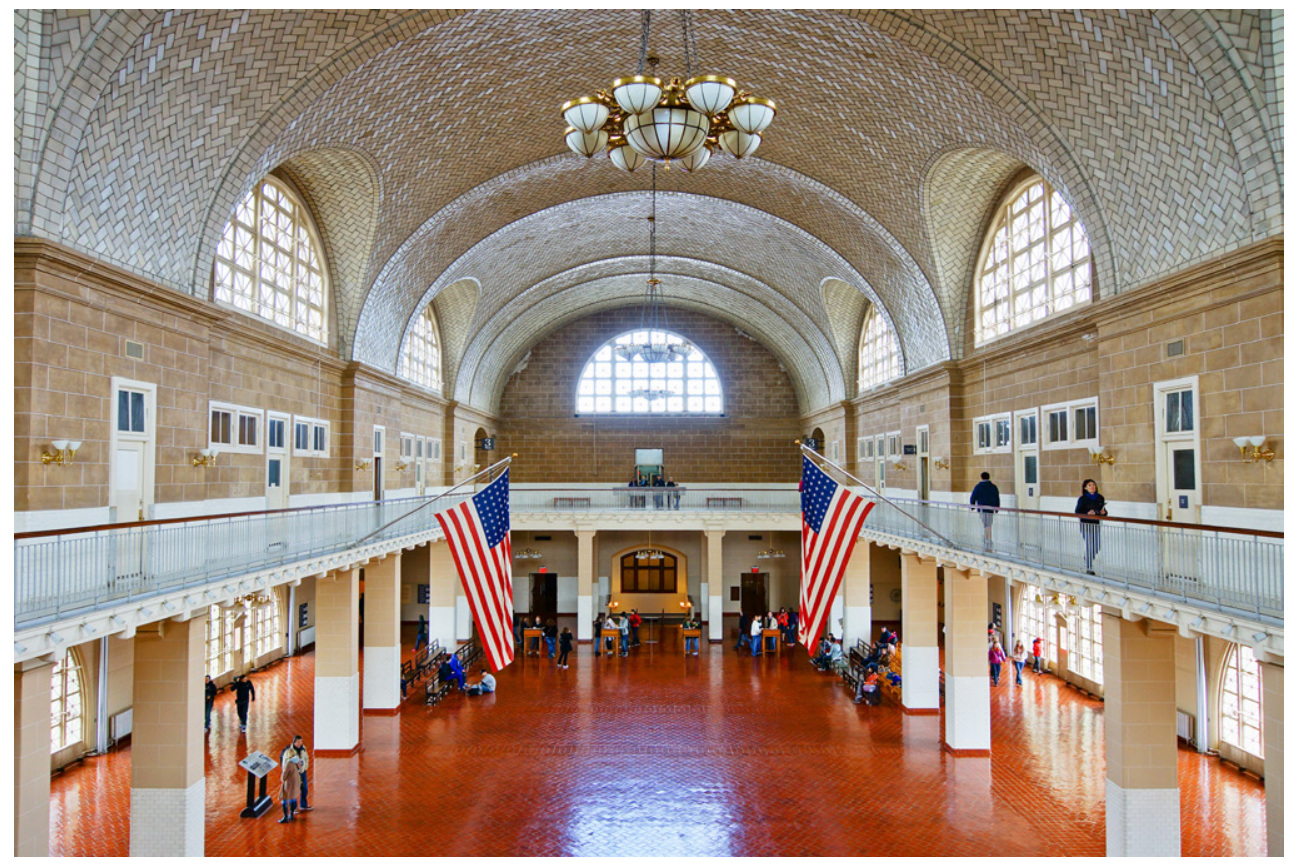

Figure 4: Ellis Island

When the architectural context does not embody such meanings in itself, a similar role is performed by the already-mentioned immersive spaces, designed to reproduce realistic meaningful spaces related to the migration experience narrated by the museum, such as ships, trains, stations, halls, border checkpoints. In the German Emigration Center, for example, the whole exhibition is based on full-scale immersive reconstructions. In that respect, the Ballinstadt Emigration Museum in Hamburg is a very emblematic example. Located on the Elbe River, the museum consists of three buildings that are philological reconstructions of the original Emigration Halls built by HAPAG (Hamburg-America Line), the shipping company formerly located in this area. The buildings host several facilities, including an information centre, shops, a restaurant, a research centre, and a permanent exhibition that at its turn makes large use of different reconstructions such as staterooms and other spaces onboard liners, an infirmary, checkpoints, and street views.

Joachim Baur, who analyzed immigration museums overseas, identifies recurring elements similar to some of those mentioned above. While describing recurring objects, reconstructions and the choice of historical venues, he defines them as 'visual metaphors' and 'containers', and acknowledges their highly symbolic value, exploited by the museum empowering their intrinsic cohesive force to nurture a feeling of 'unity in diversity'. In these museums, he argues, these apparatuses contribute to the construction and representation of 'common' or 'shared experiences of immigration' and are a kind of embodiment of the imagined community that the museum aims to establish through its narrative (Baur 2010b). These display structures are also largely used in European migration museums, however with slightly different purposes. They undoubtedly work in strong synergy with both the museum narrative and collection by: completing and emphasizing the museum's narrative; implementing the collection and compensating for the lack or shortage of significant objects; enhancing the display of those objects that may not have a strong visual impact - such as letters, small personal objects, pictures; as well as providing a support for 'immaterial' exhibits - records, films, documentaries, and personal testimonies - that often constitute a relevant part of the museum collection. One of their fundamental purposes however, as mentioned above, is to 
act as interactive devices aimed at engaging visitors and spurring them to empathize with the stories that are being told.

These experiences seem to be very successful. The visual language that was borrowed from immigration museums overseas and adapted as described above, first appeared in European emigration museums and then spread out, influencing the design of a great number of new galleries devoted to the history of emigration as well as temporary exhibitions.

\section{A Variation on the Theme: Exhibiting Immigration}

A variation on the usual concerns of exhibition techniques and design can be identified in those museums and exhibitions, though they are actually a minority, where the focus is on immigration rather than on the history of emigration. Immigration museums in Europe developed roughly at the same time as emigration museums: the Museu d'Història de la Immigraciò de Catalunya in Barcelona, inaugurated in 2004; the Musée de l'Histoire de l'Immigration in Paris - formerly Cité Nationale de l'Histoire de l'Immigration - opened in 2007; or the Immigrantmuseet in Farum, whose first exhibition dates back to 2001 (Cimoli 2013).

A relevant example of such a different approach in exhibition design is represented by the Museum of the History of Immigration in Catalonia in Barcelona. While the exhibition on twentieth-century Spanish migration displayed on board of the El Sevillano train largely draws on the above-mentioned mise-en-scène, the section about contemporary immigration in the outdoor area of the museum resorts to a diverse design model. Worthy of mention is the display devoted to the border. Here the remarkable curatorial attempt to present the concept of border as a 'non univocal, unchanging concept', and as 'physical and administrative threshold' as well as 'a psychological and cultural space' (quotes are taken from the museum's wall texts), results not only in the displayed items but also in the exhibition design. The setting is constituted by a conceptual representation of a border: a 10-metre-long tunnel made of iron portals and covered with a simple metal grill. The exhibition is arranged within and around this tunnel and the metal grill constitutes a semi-transparent although not permeable limit. The design of the tunnel recalls a jail and, at the same time, it reminds the visitor of barriers at check-points, which spatially and figuratively evoke the multiple meanings of a border. It also serves as display support - profitably resistant to atmospheric agents - for double-sided panels, images and graphics printed on metal supports and simply hung on iron wires with clamp bolts and screws. Wall texts provide short quotes and texts in Catalan, also translated into Spanish and English, which offer different critical interpretations of the border and ultimately aim at raising questions and stimulating reflections on its presence in people's daily life. Selected and visually strong images complement the texts while smaller graphics - including pictures, such as a number of reproductions of passports and green cards, as well as an original 'migrant signage' inspired by ordinary urban and road signs - enrich the iconographic apparatus of the installation. Another interesting case is represented by those exhibitions on immigration that were realized as complementary sections to previous displays dedicated to the subject of emigration. The Bremenhaven Museum in 2012 expanded its permanent exhibition by adding a new gallery on immigration which was eventually developed with a slightly different museological approach than the one adopted in the galleries devoted to the history of emigration, but drawing upon a very similar exhibition design and visual language (Bongert 2014).

By contrast, in the MeM-Memory and Migration gallery at the Genoa sea museum the two exhibitions present significant differences in their design. The gallery indeed consists of two parts: the first one, opened in 2008, is based on the exhibition La Merica! Da Genova a Ellis Island, il viaggio per mare negli anni dell'emigrazione italiana, and is devoted to the history of Italian emigration to America and Brazil; the second smaller one was inaugurated in 2011, and focuses on recent immigration to Italy (Campodonico 2008; 2014; Cimoli 2013; $2014 ; 2015)$. In the first part, admittedly inspired by the Ellis Island Museum and the German Emigration Center of Bremenhaven, the display mainly uses the consolidated format described above. In this section, the visit is structured as a role-playing game. The visitor receives a passport at the entrance of the exhibition, which assigns him/her a 'migrant identity'. Thus, the exhibition itinerary is structured around the different moments of the emigration voyage: from the departure from the Genoa harbor on board a liner until the arrival in a new country. 
A number of reconstructions of ship's interiors check controls, streets and neighborhoods of the destination city - complemented with sounds and projections to make them seem more realistic - characterize the different exhibition rooms that display personal stories through the wide use of letter, audio records, and personal objects. Technological devices are largely exploited as well, including projections, touch-screens and interactive displays, some of which are activated by the passport's barcode to customize contents, hence others are conceived as 'video games', like those reproducing the language and I.Q. tests the immigrants were required to undertake upon their arrival in the United States via Ellis Island.

The two sections follow one another as the exhibition itinerary proceeds seamlessly from the reconstruction of the Ellis Island check point to the final large room devoted to contemporary immigration in Italy. Nevertheless, the shift is marked by an evident linguistic switch. It is unclear if this neat change is intentionally pursued or not, but it is undoubtedly telling. Interactive devices are still present, as well as personal objects, videos and records, images and other testimonies of different touching experiences. However, here they are being used in a more reflexive and less playful way. A central role is performed by the display of a migrants' boat that landed in Lampedusa surrounded by videos documenting the landing of illegal immigrants on the Italian coasts. Here the visitor can sit next to the boat, pick up one of the plastic water bottles lying on the bottom and use it as earphones to listen to the story of a migrant. The visual and spatial impact of this object is quite striking as it carries a very significant story with a strong message that is also amplified and conveyed by the physical interaction with it.

Other displays require the visitor's interaction to activate the contents focusing on different topics and aimed at recounting rough stories of migrants, the hardship of their travel to Italy while highlighting and refuting stereotypes and prejudices about immigrants and their impact on Italian society. Period rooms and reconstruction are not pervasively present any more, and role-play dynamics do not structure the visit any longer. The exhibition always aims to nurture empathy in the visitor through the stories that are told, but also - and more explicitly - to raise questions and foster reflection on the issues that the exhibition investigates. For

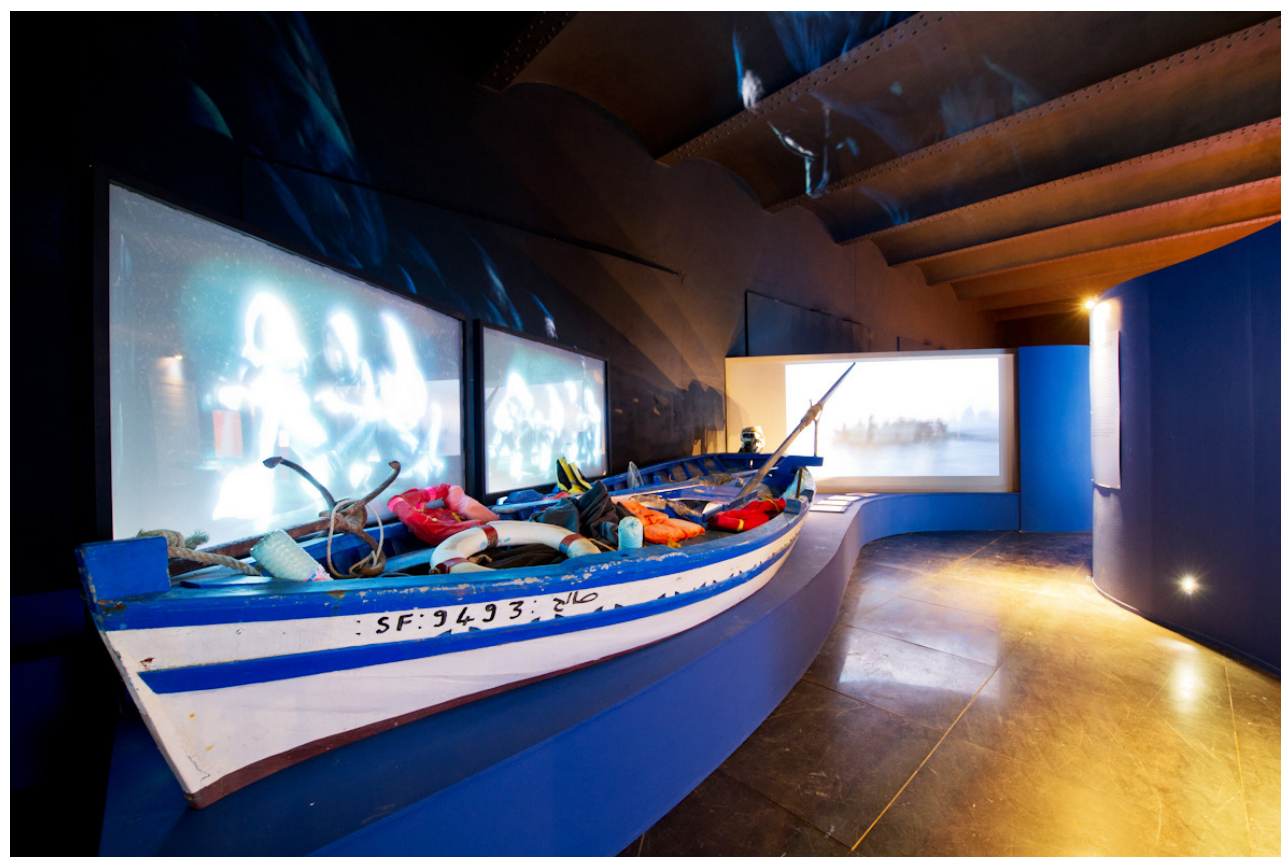

Figure 5: Genoa Mem 2 
example, in the small rooms called 'reflection niches', visitors engage in a kind of talk with the curators, i.e. a dialogue based on questions and answers focusing on some of the most common misleading information and stereotypes about immigration and immigrants' impact on Italian society. Although the videos are too long - and as a consequence the visitor may become impatient - they represent an interesting approach that is worth developing further. Despite the small space dedicated to this gallery, which perhaps results in a dense narration with too many inputs for the visitor, it is clearly an attempt to make room for a personal reflection.

We may say that, looking at the exhibition design that has been implemented in immigration museums, although occasionally influenced by the above mentioned solutions, it seems that they are less formalized and standardized compared to emigration museums: recurring master themes such as the voyage and crossing borders are still present, as well as iconic objects, personal testimonies and interactive devices aimed at emotionally provoking the visitor. Nevertheless, their use is less descriptive and more conceptual and figurative.

\section{A Codified Visual Language}

The different exhibition design models of immigration exhibitions compared to those dedicated to emigration, can be partially traced back to their different audiences. As a matter of fact, while emigration museums are mostly visited by students and families, immigration museums, due to the awkwardness of the topic, are usually targeted at a more mature audience. This necessarily influences their design: for example, the firsts are often inspired to use playful solutions while the latter tend to be more abstract and suggestive. The time frame of the phenomena that these exhibitions describe also seems to influence their design. The shift in the visual language adopted is indeed evident when the exhibition deals with contemporary phenomena rather than with historical facts. The former, commonly immigration exhibitions, often resort to temporary displays where artworks, videos, and graphic design play an important role. A representative and well-known example of this approach is the permanent exhibition Repères at the Musée de l'Histoire de l'Immigration in Paris, largely based on art installations. The second ones, usually emigration museums, involve permanent galleries, whose design is often based on large, expensive and binding solutions, such as full-scale reconstructions.

A common feature is to draw upon design solutions largely characterized by the intention to stimulate empathy in the visitor toward the story told and aimed at achieving a greater visitor involvement: several display structures, devices and exhibition strategies are implemented according to this purpose. New technologies and technological devices are largely employed and can offer some interesting possibilities: they are changeable, can allow multiple entry points, facilitate cross-disciplinary references, provide different levels of access to contents, and foster participation. However, it currently seems that these technologies are not a real solution, or at least they are not as relevant as they are thought to be, and often cause problems. The costs of these devices and their maintenance, for example, should be carefully considered and their reliability improved since, when a relevant part of the content of an exhibition relies on technological devices and displays, their failure to work ultimately causes a gap in the flow of information that is being addressed to the visitor.

Immersive spaces, real-scale reconstructions, recurring common iconic objects, and highly scenographic and interactive displays, are also undoubtedly efficacious: they have a strong visual impact that make it easier to understand and remember what's on display. Moreover, their striking aesthetic and immediate non-verbal impact contribute to their communicative effectiveness, especially amongst the youngest. Nevertheless, they also have some drawbacks. As different authors have already pointed out, the overuse of iconic objects like passports and luggage is transforming them from precious multilayered communication tools, into stale, prosaic clichés (Poehls 2011). Another risk, no less problematic, is lurking in the extensive use of full-scale reconstructions: they may in fact result in too literal transpositions, leaving little to the visitor's imagination and limiting personal interpretations, thus eventually flattening and homogenizing the visit experience.

Eventually, immersive spaces, together with the overexploitation of solutions and tools inspired by role-playing game and computer gaming techniques, and the large use of technological and interactive devices, typical of many of these museums, may transform the visit 
into a funfair-like experience targeted only at the youngest. These exhibitions may thus result in oversimplification and ultimately be unable to raise questions or foster other perspectives or dissent, thus failing to create the context for reflection and serious contemplation that the topic of migration deserves. Hence, though aiming to enrich the visitor's experience through its impact, this kind of exhibition design may be narrowed in its scope. And so, without appealing to a wider audience of youngsters and adults, it is unlikely to be explored and experienced with the requisite degree of freedom and reflexivity.

Today, while several museums are dealing with issues of migration and cultural diversity, it is desirable that the effort to reassess their approaches and practices is coupled with careful thought about the approach to adopt concerning the design of these exhibitions. "What is said' - Parry and Saweyer remind us, drawing on McLuhan - 'is deeply influenced by the medium through which it is said' and 'museums have always been influenced by the devices and strategies used to manage and display their understanding and their collections' (Parry and Saweyer 2005: 44, 40). A museum is a multimedia and multimodal space of knowledge, education and communication: the role of exhibition design and museum spaces should not be underestimated in their contribution to conveying - enhancing or hiding - the museum messages. Their design should be developed in a strict synergy with the construction of the museum narratives and definition of its main messages since the way in which these are displayed ultimately affects their perception. When the exhibition design and display structures are too pervasive and prevailing, they can overwhelm the message, distract and disturb its comprehension. Conversely, they might contribute by supplying different alternative layers, stimulating the visitor's emotional, intellectual and physical participation, and transform the museum visit into an experience that opens the mind, an occasion of knowledge and reflection that makes it possible to better know and understand the world.

Received $8^{\text {th }}$ January 2015

Finally Accepted 23rd November 2015

\section{Notes}

1 The term 'museography' refers to a complex set of disciplines and competences that relate to the act of displaying, understood as the result of the interrelationship between theoretical reflections and practice, between curating, architecture and display. It encompasses the study and analysis of the physical structure and spatial layout of museums which are investigated not only in their architectural outcome but as tied in with the use, narratives and mission of the museum itself (Lugli 1992; Grewcock 2013).

2 More specifically, the paper builds on the research activities and findings of the research project MeLa - European Museums in an Age of Migrations, funded within the European Union's Seventh Framework Programme (2011-2015). Adopting the notion of migration as a paradigm of the contemporary global and multi-cultural world, the MeLa Project investigated the evolution of European museums as physical places, cultural spaces and processes within the framework of the present political, social and cultural context, characterized by accelerated mobility, fluid circulation of information, ideas and cultures, and the consequent increase of cultural encounters, cross-fertilization and hybridization of societies and identities. By exploring the challenges as well as the opportunities resulting from this 'age of migrations,' MeLa aimed to identify innovative policies and practices which may enhance the role of museums in actively promoting social cohesion and enhancing the entrenchment of an inclusive European identity (Basso Peressut and Pozzi, 2012; www. mela-project.eu).

3 Janet Marstine in her compendium New Museum Theory and Practice, drawing on HooperGreenhill (2000), refers to this kind of museum as a post-museum, 'a site from which to redress social inequalities [...] [that] can promote social understanding' (2006: 19). In this regard, we are also reminded of Clifford's idea, based on the thinking of Louise Pratt, of museums as contact zones (Pratt 1991; Clifford 1997), and of the view, built on Homi Bhabha theories, of museums as a third space 'that 'enables other positions to emerge' (Rutherford 1990: 211; Bhabha 1994; Bodo 2009; Schorch 2013). 
4 Several nationally and internationally funded research projects, run by academics, networks of museums and other cultural institutions, have been focusing recently on the issue of museums, identity, migrations and intercultural dialogue, largely contributing to the debate and to the advancement of the knowledge and practice in the field. Examples include, but are not limited to: Born in Europe (2000-2005), a five-year project funded by the European Commission under the Culture 2000 Programme, which focused on issues of migration representation, identity and citizenship in contemporary Europe, and resulted in the project for an exhibition series (Ipsen and Olesen, 2003; Gößwald, 2007); Map for ID: Museums as places for intercultural dialogue (2007--2009), a project supported by the Lifelong Learning Programme of the European Union, which aimed to develop innovative practices to improve a more active engagement of museums with local multi-cultural communities (Bodo et al., 2009; www.amitie.it/mapforid/index1.htm); Migration in Museums: Narratives of Diversity in Europe (2007), a research programme conducted by the Network Migration in Europe and financed by the Capital City Culture Fund (Hauptstadtkulturfonds) with the support of the European Union and aimed at exploring the issue of the representation of migration in museums (Ohliger, 2009; www.network-migration.org/pr_migration_museum_eng.php). Moreover, the EU recently funded two major projects under the Seventh Framework Programme, focusing on museums and identity: Eunamus - European National Museums: Identity Politics, the Uses of the Past and the European Citizen (2010-2013), which investigated the creation and power of European national museums, focusing on understanding the conditions for using the past in negotiations that recreate citizenship, and on the understanding of layers of territorial belonging (Knell et al., 2011; www.ep.liu.se/eunamus) and MeLa - European Museums in an Age of Migrations (2011-2015), that adopting the notion of 'migration' as a paradigm of the contemporary global and multicultural world, was conceived to reflect on the evolution of museums' role in the twenty-first century transcultural Europe and their contribution in shaping European identity (Basso Peressut and Pozzi, 2012; www.melaproject.eu).

5 The reassessment of the scope, role and nature of objects in exhibitions devoted to migration is a central issue upon which several studies are being recently focused as well as different curatorial experimentations. On this issue see Poehls 2011; Whitehead et al. 2014.

6 The exhibition was mainly funded by the European Union and promoted by the Haus der Geschichte der Bundesrepublik Deutschland in collaboration with other eight museum partners. It travelled for three years in eight countries, therefore it was designed in order to be moved and customized in the easiest way, according to the needs of each hosting institution.

\section{References}

Appadurai, A. (1996) Modernity at Large, Minneapolis: University of Minnesota Press.

Basso Peressut, L. (2005) II museo moderno, Milan: Lybra.

Basso Peressut, L., Lanz, F., and Postiglione G. (eds) (2013) European Museums in the 21st Century: Setting the Framework, Milan: Politecnico di Milano. http://www.melaproject.eu/publications (accessed 10 Oct. 2015).

Baur, J. (2009) 'Five Thoughts on a Migration Museum that I Wish for', in Rainer Ohliger (ed.) Migration in Museums: Narratives of Diversity in Europe, 18-20, Essays of the Conference "Migration in Museums: Narratives of Diversity in Europe" Berlin, October 23-25, 2008 (unpublished document).

(2010a) 'Il museo dell'immigrazione', Nuova museologia, 22: 2-8. 
(2010b) 'La rappresentazione della Migrazione', Nuova museologia, 22: 27-34.

(2013) 'Museum and Nation', in Luca Basso Peressut, Francesca Lanz, and Gennaro Postiglione (eds) op cit., 331-41.

Bhabha, H. K. (1994) The Location of Culture, London \& New York: Routledge.

Bodo, S. (2009) 'Sviluppare "spazi terzi”: una nuova sfida per la promozione del dialogo interculturale nei musei', in Anna Maria Pecci (ed.), Patrimoni in migrazione.

Accessibilità, partecipazione, mediazione nei musei, 75-84, Milan: FrancoAngeli.

Bodo, S., Gibbs, K., Sani, M. (eds) (2009) Museums as places for intercultural dialogue: selected practices from Europe, MAP for ID. online.ibc.regione.emilia-romagna.it/// libri/pdf/Manuale MAPforlD.pdf (accessed 10 Oct. 2015).

Bongert , C. (2014) '“Passage" - The German Emigration Center as Immigration Museum. Some Reflections on the New Permanent Exhibition', in Francesca Lanz, and Elena Montanari (eds) op. cit., 23-9.

Campodonico, P. (2008) ‘ll Percorso della Mostra', in "La Merica!” - 1892-1914. Da Genova a Ellis Island, il Viaggio per Mare negli Anni dell'Emigrazione Italiana, 8-23, Genoa: SAGEP.

(2014) 'Building the Migrant Memory', in Francesca Lanz, and Elena Montanari (eds) op cit., 30-37.

Chambers, I. (2012) 'The Museum of Migrating Modernities', in Beatrice Ferrara (ed.) Cultural Memory, Migrating Modernities and Museum Practices, 13-32, Milan: Politecnico di Milano. http://www.mela-project.eu/publications (accessed 10 Oct. 2015).

Chambers, I., De Angelis, A., lanniciello, C., Orabona, M., and Quadraro, M., (eds) (2014) The Postcolonial Museum: The Arts of Memory and the Pressures of History, Farnham: Ashgate.

Cimoli, A.C. (2013) 'Migration Museums in Europe: Narratives and their Visual Translations', in Luca Basso Peressut, Francesca Lanz, and Gennaro Postiglione (eds) op cit., 313-407.

Cimoli, A. C., (2014) Immigration: politics, rhetoric and participatory practices in Italian museums, in Gouriévidis (ed) op cit., 83-102.

(2015) Identity, Complexity, Immigration: Staging the Present in Italian Migration Museums, in Whitehead, C., Eckersley, S., Lloyd, k., and Mason, R (eds), 285-315.

Clifford, J. (1997) 'Museums as Contact Zones', in Routes. Travel and Translation in the Late Twentieth Century, 188-219, Cambridge, MA: Harvard University Press.

du Mazaubrun, H., and Tadros R. (2014) 'Le Musée de l'histoire de l'immigration et la société civile. L'exemple d'une collection en chantier', in Francesca Lanz, and Elena Montanari (eds) op cit., 38-48.

Eick, S. (2013) 'The German Emigration Center', in Luca Basso Peressut, Francesca Lanz, and Gennaro Postiglione (eds) op cit., 343-6.

Giebelhausen, M. (2006a) 'The Architecture is the Museum', in Janet Marstine (ed) New Museum Theory and Practice: An Introduction, 41-63, Oxford: Blackwell. 
(2006b) 'Museum Architecture: A Brief History', in Sharon Macdonald (ed.) A Companion to Museum Studies, 223-244, Oxford: Blackwell.

Gößwald, U., (2007) 'Project Report: Born in Europe: an International Programme on Representing Migrant Experiences in European Museum', International Journal of Intangible Heritage, (2) 138-144. www.ijih.org/volumeMgr. ijih?cmd=volumeView\&volNo=2\&manuType=02 (accessed 10 Oct. 2015).

Gouriévidis, L., (ed.) (2014) Museums and Migration: History, Memory and Politics, London: Routledge.

Grewcock, D. (2013) Doing Museology Differently, London: Routledge.

Hooper-Greenhill, E. (1992) Museums and the Shaping of Knowledge, London: Routledge.

(2000) Museums and the Interpretation of Visual Culture, London: Routledge.

Innocenti, P., (ed.) (2012) European Crossroads: Museums, Cultural Dialogue and Interdisciplinary Networks in a Transnational Perspective, Milan: Politecnico di Milano. http://www.mela-project.eu/publications (accessed 10 Oct. 2015 February 2014).

(ed) 2014, Migrating Heritage: Experiences of Cultural Networks and Cultural Dialogue in Europe, Aldershot: Ashgate.

Ipsen, M. and Olesen, B. (ed.) (2003) Born in Europe, Gylling: Narayana Press.

Karp, I., and Lavine, S.D. (eds) (1991) Exhibiting Cultures: The Poetics and Politics of Museum Display, Washington: Smithsonian Institution.

Karp, I., Mullen Kreamer, C., and Lavine, S. D. (eds) (1992) Museums and Communities: The Politics of Public Culture, Washington: Smithsonian Institution.

Karp, I., Kratz, C. A., Szwaja, L and Ybarra-Frausto, T. (eds) (2006) Museum Frictions: Public Cultures/Global Transformations, Durham: Duke University Press.

Knell, S. J., MacLeod, S., and Watson, S., (eds) (2007), Museum Revolutions: How Museums Change and are Changed, London and New York: Routledge.

Knell, S., Aronsson, P. and Bugge Amundsen, A. (eds) (2011) National Museums: New Studies from Around the World, Abingdon: Routledge.

Lanz, F., and Montanari E. (eds) (2014) Advancing Museums Practices. Turin: Allemandi. http://www.mela-project.eu/publications (accessed 10 Oct. 2015).

Lugli, A. (1992) Museologia, Milan: Jaca Book.

Macdonald, S. (2003) 'Museums, National, Postnational and Transcultural Identities', Museum and Society, 1 (1): 1-16. https://www2.le.ac.uk/departments/ museumstudies/museumsociety (accessed 10 Oct. 2015)

(ed) (2006) A Companion to Museum Studies, Oxford: Blackwell.

Macdonald, S., and Fyfe, G. (eds) (1998) Theorizing Museums: Representing Identity and Diversity in a Changing World, Oxford: Blackwell.

Marstine, J. (ed) (2006) New Museum Theory and Practice: An Introduction, Oxford: Blackwell. 
Marstine, J., Bauer, A. A., and Haines, C. (eds) (2013) New Directions in Museum Ethics, London: Routledge.

Parry, R., and Saweyer, A. (2005), 'Space and the Machine', in Suzanne MacLeod (ed.) op cit., 39-51.

Poehls, K. (2011) ‘Europe, Blurred: Migration, Margins and the Museum', Culture Unbound: Journal of Current Cultural Research, 3: 337-53.

Pratt, M. L. (1991) 'Arts of the Contact Zone', Profession, 91: 33-40.

Rutherford, J. (ed.) (1990) Identity. Community, Culture, Difference, London: Lawrence \& Wishart.

Sandell, R. (ed.) (2002) Museums, Society, Inequality, London: Routledge.

Schorch, P. (2013) 'Contact Zones, Third Spaces, and the Act of Interpretation', Museum and Society, 11(1): 68-81. https://www2.le.ac.uk/departments/museumstudies/ museumsociety (accessed 10 Oct. 2015)

Vergo, P. (ed.) (1989) The New Museology, London: Reaktion Books.

Watson, S. (2007) (ed.) Museums and their Communities, London, Routledge.

Welsch, W. (1999) 'Transculturality: The Puzzling Form of Cultures Today', in Mike Featherstone and Scott Lash (eds) Spaces of Culture: City, Nation, World, 194-213, London: Sage Publications.

Whitehead, C., Lloyd, K., Eckersley, S., and Mason, R. (eds) (2015) Museums, Migration and Identity in Europe. Aldershot: Ashgate.

Whitehead, C., Eckersley, S., and Mason, R., (2012) Placing Migration in European Museums: Theoretical, Contextual and Methodological Foundations. Milan: Politecnico di Milano. http://www.mela-project.eu/publications (accessed 10 Oct. 2015).

*Francesca Lanz, Architect and PhD in Interior Architecture and Exhibition Design, she is Lecturer at the Department of Architecture and Urban Studies of Politecnico di Milano. Since 2006 she has been teaming up with different POLIMI departments, collaborating as associate researcher and research fellow on several national and international research projects and teaching activities. Most recently, she has been contributing to the EU funded Research Projects MeLa - European Museums in an age of migrations (2011-2015). and TRACES - Transmitting Contentious Cutlural Heritage with the Arts (2016-2019)..

Address: Politecnico di Milano, Department of Architecture and Urban StudiesPiazza Leonardo da Vinci 26, 20133 Milano, Italy

Francesca.lanz@polimi.it 